\title{
COMPARISON OF ROLL DEFORMATION IN 4HI ROLLING MILL AND 20 HI ROLLING MILL DUE TO THERMAL STRESSES, OVERLOADING, SPALLING AND DESIGN PARAMETERS
}

\author{
Dr Ravi Kumar Goyal \\ Mechanical Engineering Department, Jaipur Institute of Technology \\ Mahindra SEZ, Jaipur (Rajasthan), India
}

Anurag Joshi

Mechanical Engineering Department, University of Engineering \& Management Sikar Road, NH-11, Jaipur (Rajasthan), India

Umesh Gurnani

Mechanical Engineering Department, University of Engineering \& Management Sikar Road, NH-11, Jaipur (Rajasthan), India

\begin{abstract}
The Rolling mill roll deformation is a serious problem and directly impact on production capacity, Mill Environment, Quality and highly impacting financial viability of the production companies. In this research paper the data taken from three companies, Supreme Rolls and Shears Pvt Ltd Indore, Dee Tee Industries Indore, ASSIL Industires Jaipur and Ruchi Strips and Alloys Ltd Indore. The first two companies are producing rolls for other two companies. Second Company is having 4Hi Rolling and Third Company is having $20 \mathrm{Hi}$ Rolling Mill. The Deformation analysis is strictly subjected to the Work Rolls. The deformation is done on four basic parameters like Thermal Stresses, Overloading, Spalling and Design faliures.
\end{abstract}

Key words: Rolling Mill, Thermal Stresses, Spalling, Overloading

Cite this Article: Dr Ravi Kumar Goyal, Anurag Joshi and Umesh Gurnani, Comparison of Roll Deformation In 4hi Rolling Mill and 20 Hi Rolling Mill Due To Thermal Stresses, Overloading, Spalling and Design Parameters. International Journal of Design and Manufacturing Technology 7(1), 2016, pp. 07-22.

https://iaeme.com/Home/issue/IJDMT?Volume $=7 \&$ Issue $=1$ 


\section{INTRODUCTION}

There are various reasons by which the damage in the cold rolling mill rolls occurs. The main objective is to highlight those reasons which are responsible for the breakage. The parameters considered during the manufacturing and during the regular use of rolls in cold rolling in the past researches and the effect of these parameters to increase the life of a roll. These are based upon the various factors and summarize the effect of parameters responsible for the deformation concluded by the various researchers in the past history of cold rolling mill. Rolling is one of the oldest procedures for the production of sheet metal. The Hot Rolled and Cold Rolling Processes are different in nature and in output also. The Rolls are the main tool for the rolling process and the life of the roll is having a direct impact on the economic status of a rolling mill. The designing of the roll is much dependent on the geometric shape of the sheet. In small diameter roll a thin sheet can be produced, whereas large diameter rolls can produce medium thickness of the sheet. The life of the roll can be increased if they use properly and should be analysed when they permanently deformed under the load conditions. The life to roll is also governed by the initial stage of manufacturing of the roll. The selection of material, the production sequence, heat treatment and machining are having vital importance on the life of a roll. The mechanical properties, hence are greatly affected if the process parameters are changed. The main objective of this work is to identify the reasons for roll deformation in the rolling mill. The work is determined by detailing the role manufacturing at Supreme Rolls and Shears Pvt Ltd, Indore and Dee Tee Industries, Indore which are producing Rolls for various roles for Indigenous and other export suppliers. The working of the rolls in rolling mill is studied at Ruchi Strips and Alloys Ltd, Indore and ASIL Industries at Jaipur which are having 20Hi and 4Hi rolling mills and are the customers of above mentioned Roll Manufacturing Companies.

The four sections are namely

1. Deformation due to Thermal Stress.

2. Deformation due to Overloading.

3. Deformation due to Spalling.

4. Deformation due to Design.

Following abbreviations have been used in the calculations below.

1. $\mathrm{T}=$ Tension at outlet section of the mill.

2. A $=$ Area of contact of sheet and work roll.

3. $L_{p}=$ Projected length of arc of contact.

4. $b=$ Width of sheet.

5. $\Delta h=$ Difference in sheet thickness(Output - Input)

6. $T_{s t}=$ Stress due to Thermal Strain

7. $\mu=$ Friction coefficient between work roll and sheet.

8. $\mathrm{E}=$ Young's Modulus of work roll.

9. $\mathrm{R}=$ Radius of work roll.

10. $\mathrm{MM}=$ Mill modulus of mill.

11. $\Delta \mathrm{T}=$ Change in temperature at surface of work roll.

12. $\alpha=$ Linear Thermal Coefficient of temperature of work roll.

13. $\Delta \mathrm{L}=$ Change in length due to any strain. 
Comparison of Roll Deformation In 4hi Rolling Mill and 20 Hi Rolling Mill Due To Thermal Stresses, Overloading, Spalling and Design Parameters

14. $S_{t}=$ Stress due to Tension.

15. $S V=$ Saponification Value.

16. $P H=\mathrm{PH}$ value of coolant.

17. $N=$ Number of Roll deformed.

18. $Q=$ Quarter time period.

19. $T S=$ Tensile Strength of D2 material

20. $T_{s t}=$ Stress due to thermal Strain

Q1 denotes the time period from January2013- March 2013,

Q2 from April 2013 - June 2013 and

Q3 from July - September 2013.

\subsection{Process of calculation}

- Thermal Strain due to temperature change has been calculated.

- With the help of Young's Modulus of Elasticity and Thermal Strain, Thermal stress have been calculated.

- Deformation due to thermal stress have been calculated

- Stress due to Tension have been calculated by putting area as the area in contact between work roll and sheet.

- Strain is calculated by the Stress due to Tension and Young's Modulus of Elasticity.

- Both the deformations have been summed up and calculated where the deformations are more than $5 \mathrm{~mm}$.

- Number of deformations in any period due to thermal stress is calculated.

- By Mill Modulus, total amount of sheet volume per mm deformation is calculated.

- Number of roll changed has been calculated by the total deformation in a quarter and number of sheet volume produced.

- Parameter for spalling have been explained and calculated where the stress is crossing the Tensile strength and causing the fracture.

- Parameters for low friction coefficient has been studied and total number is calculated where the friction coefficient goes below the range and causes the fracture.

\subsection{Work Roll Material Properties}

The work roll for $4 \mathrm{Hi}$ and $20 \mathrm{Hi}$ is taken D2 material. The chemical and mechanical properties of D2 materials are as follows: 


\subsection{Mechanical Properties}

Table 1 Mechanical Properties of Roll Material

\begin{tabular}{|c|c|}
\hline Property & Value \\
\hline Poisson's Ratio & $0.27-0.30$ \\
\hline Young's Modulus of Elasticity & $190-210 \mathrm{Gpa}$ \\
\hline Linear Thermal Coefficient & $10.3 * 10^{-6}$ \\
\hline Tensile Strength & $1961 \mathrm{MPa}$ \\
\hline
\end{tabular}

\subsection{Chemical Composition of D2 Material:}

Table 2 Chemical Composition of Roll Material

\begin{tabular}{|c|c|c|c|c|c|c|c|c|c|}
\hline $\mathbf{C}$ & $\mathbf{M n}$ & $\mathbf{S i}$ & $\mathbf{C o}$ & $\mathbf{C r}$ & $\mathbf{M o}$ & $\mathbf{V}$ & $\mathbf{P}$ & $\mathbf{N i}$ & $\mathbf{C u}$ \\
\hline $1.2 \%$ & $0.60 \%$ & $0.60 \%$ & $1.00 \%$ & $12 \%$ & $0.70 \%$ & $1.1 \%$ & $0.03 \%$ & $0.30 \%$ & $0.25 \%$ \\
\hline
\end{tabular}

Analysis is done on two types of roles that is $4 \mathrm{Hi}$ and $20 \mathrm{Hi}$. So sequentially number of deformations theoretically can be figured out and will be compared with practical data.

The deformation of work roll of rolling mill has been divided in three sections named as Entry Elastic Deformation zone, Plastic Deformation zone, and Exit Deformation zone as shown in Fig below [26]

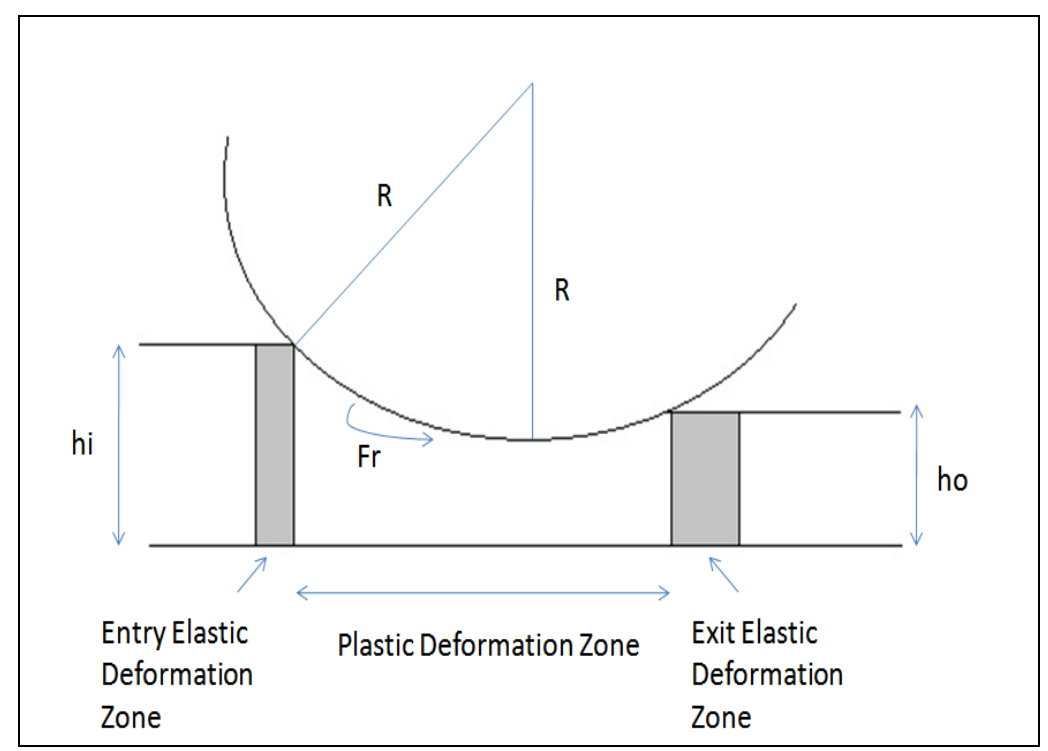

Figure 1 representation of the deformation zones

\section{DEFORMATION DUE TO THERMAL STRESS}

Thermal stress and strain are caused by temperature change. Materials expand at temperature increase and contract at temperature decrease. Restricting thermal strain cause thermal stress. Tension in the work roll according to provided data 
Comparison of Roll Deformation In 4hi Rolling Mill and 20 Hi Rolling Mill Due To Thermal Stresses, Overloading, Spalling and Design Parameters

\subsection{Sample Calculation}

$\mathrm{T}=41.5 \mathrm{kN}$

Area of tension, $\mathrm{A}=\mathrm{b} * L_{p}$

Where $\mathrm{b}$ is width of sheet and $L_{p}$ is projected length of arc of contact.

$\mathrm{A}=400 \mathrm{~mm} * L_{p}$

Now $L_{p}=\sqrt{R \Delta h}$

$[23][25]$

Where $\mathrm{R}$ is radius of work roll and $\Delta h$ is the difference of thickness of sheet.

Here $\Delta h$ is $0.2 \mathrm{~mm}$

And $\mathrm{R}$ is $125 \mathrm{~mm}$

So $L_{p}=\sqrt{25 m m * m m}$

$\mathrm{A}=400 * 5 \mathrm{~mm}^{2}$

So Stress due to tension is, $S_{t}=\mathrm{T} / \mathrm{A}$

$=41.5 \mathrm{kN} / 2000 \mathrm{~mm}^{2}$

$=20.75 \mathrm{MPa}$

Strain $=$ Stress $/$ Young's Modulus

$=20.75 / 210$

$\Delta \mathrm{L} / \mathrm{L}=20.75 / 210$

$\Delta \mathrm{L} \sim \mathrm{L} / 10$

Now in our case the diameter is $250 \mathrm{~mm}$, so $\mathrm{L}=250 \mathrm{~mm}$

$\Delta \mathrm{L}=2.5 \mathrm{~mm}$.

A more deformation of $2.5 \mathrm{~mm}$ can cause the role to change.

Whenever the $\mathrm{PH}$ values goes low, the coolant is unable to provide the required cooling and the temperature temporary increases up to $200-250{ }^{\circ} \mathrm{C}$

Thermal Strain $=\alpha . \Delta \mathrm{T}$

For D2 material value of $\alpha$ is $10.3 * 10^{-6} \mathrm{~mm} / \mathrm{mm}{ }^{\circ} \mathrm{C}$

So, the temperature deviation from room temperature is

$(250-25){ }^{\circ} \mathrm{C}=225^{\circ} \mathrm{C}$

So thermal strain is

$T_{s}=10.3 * 225 * 10^{-6} \mathrm{~mm} / \mathrm{mm}$

$=2340 * 10^{-6} \mathrm{~mm} / \mathrm{mm}$

Now,

Strain $=\Delta \mathrm{L} / \mathrm{L}$.

So, 
$2340 * 10^{-6}=\Delta \mathrm{L} / \mathrm{L}$.

In our case the length is $400 \mathrm{~mm}$

$\Delta \mathrm{L}=0.936 \mathrm{~mm}$.

Similarly,

Whenever the Saponification values goes low, the coolant is unable to provide the required cooling and the temperature temporary increases up to $200-250{ }^{\circ} \mathrm{C}$

Thermal Strain $=\alpha . \Delta \mathrm{T}$

Here is our case, for D2 material value of $\alpha$ is $10.3 * 10^{-6} \mathrm{~mm} / \mathrm{mm}{ }^{\circ} \mathrm{C}$

So, the temperature deviation from room temperature is

$(250-25){ }^{\circ} \mathrm{C}=225^{\circ} \mathrm{C}$

So thermal strain is

$T_{s}=10.3 * 225 * 10^{-6} \mathrm{~mm} / \mathrm{mm}$

$=2340 * 10^{-6} \mathrm{~mm} / \mathrm{mm}$

Now,

Strain $=\Delta \mathrm{L} / \mathrm{L}$.

So,

$2340 * 10^{-6}=\Delta \mathrm{L} / \mathrm{L}$.

In our case the length is $400 \mathrm{~mm}$

$\Delta \mathrm{L}=0.936 \mathrm{~mm}$.

Similarly when the coolant status goes low, the temperature rises and a further deformation of $0.936 \mathrm{~mm}$ occurs as shown above by other factors.

So total deformation due to tension and temperature changes due to $\mathrm{PH}$ value, coolant and saponification value is $5.308 \mathrm{~mm}$ which will deform the role and make it unusable

Total number of times from 90 days when the temperature rises such high due to thermal stress value in Jan - March $=6$ times .

Total number of times from 90 days when the temperature rises such high due to thermal stress value in Apr - June $=10$ times

Total number of times from 90 days when the temperature rises such high due to thermal stress value in Jun - Aug = 4 times.

Table 3 Research Parameters for Thermal Stresses

\begin{tabular}{|c|c|c|c|c|c|c|c|c|c|}
\hline $\mathbf{Q}$ & $\begin{array}{c}\mathbf{T} \\
(\mathbf{k N})\end{array}$ & $\begin{array}{c}\boldsymbol{L}_{\boldsymbol{p}} \\
(\mathbf{m m})\end{array}$ & $\begin{array}{c}\Delta \boldsymbol{h} \\
(\mathbf{m m})\end{array}$ & $\begin{array}{c}\mathbf{R} \\
(\mathbf{m m})\end{array}$ & $\mathbf{S V}$ & $\boldsymbol{T}_{\boldsymbol{s}}\left(\mathbf{1 0}^{-\mathbf{6}}\right)$ & $\begin{array}{c}\boldsymbol{S}_{\boldsymbol{t}} \\
(\mathbf{M P a})\end{array}$ & $\mathbf{P H}$ & $\mathbf{N}$ \\
\hline Q1 & 41.5 & 5 & 0.2 & 125 & 188.35 & 2340 & 20.75 & 8.64 & 6 \\
\hline Q2 & 41.5 & 5 & 0.2 & 125 & 184.28 & 2340 & 20.75 & 8.14 & 10 \\
\hline Q3 & 41.5 & 5 & 0.2 & 125 & 183.28 & 2340 & 20.75 & 7.46 & 4 \\
\hline
\end{tabular}


Comparison of Roll Deformation In 4hi Rolling Mill and 20 Hi Rolling Mill Due To Thermal Stresses, Overloading, Spalling and Design Parameters

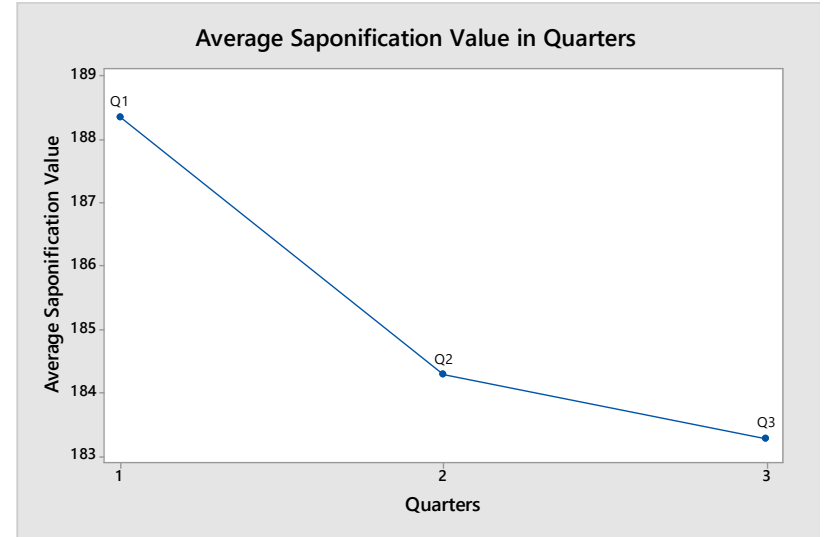

Figure 2 saponification value vs three quarters (graph 1)

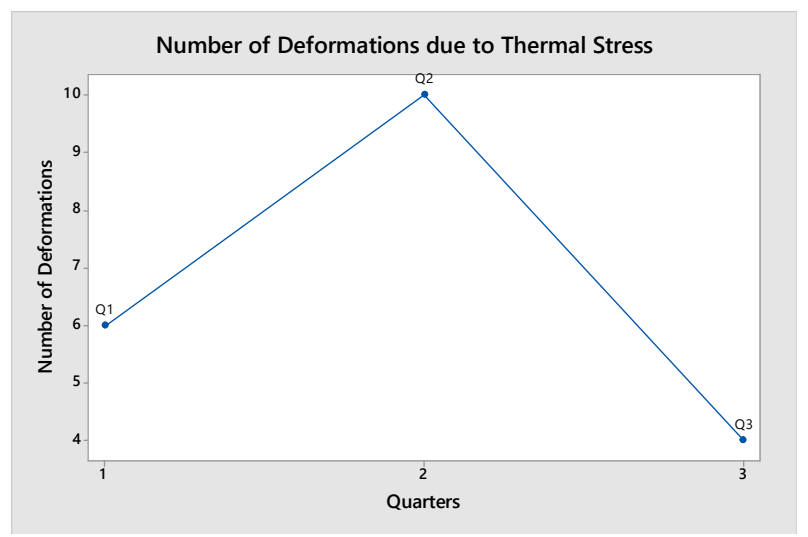

Figure 3 number of deformations vs three quarters (graph 2)

\subsection{Sample calculation for 20High Mill}

Thermal stress and strain are caused by temperature change. Materials expand at temperature increase and contract at temperature decrease. Restricting thermal strain cause thermal stress.

Tension in the work roll according to provided data

$\mathrm{T}=50 \mathrm{kN}$

Area of tension, $\mathrm{A}=\mathrm{b} * L_{p}$

Where $\mathrm{b}$ is width of sheet and $L_{p}$ is projected length o arc of contact.

$\mathrm{A}=1000 \mathrm{~mm} * L_{p}$

Now $L_{p}=\sqrt{R \Delta h}$ .[23][25]

Where $\mathrm{R}$ is radius of work roll and $\Delta h$ is the difference of thickness of sheet.

Here $\Delta h$ is $0.2 \mathrm{~mm}$

And $\mathrm{R}$ is $30 \mathrm{~mm}$

So $L_{p}=\sqrt{6 m m * m m}$

$\mathrm{A}=1000 * 2.44 \mathrm{~mm}^{2}$ 
So Stress due to tension is, $S_{t}=\mathrm{T} / \mathrm{A}$

$=50 \mathrm{kN} / 2440 \mathrm{~mm}^{2}$

$=20.49 \mathrm{MPa}$

Strain $=$ Stress $/$ Young's Modulus

$=20.49 / 210$

$\Delta \mathrm{L} / \mathrm{L}=20.49 / 210$

$\Delta \mathrm{L} \sim \mathrm{L} / 10$

Now in our case the radius is $30 \mathrm{~mm}$, so

$\Delta \mathrm{L}=3 \mathrm{~mm}$.

A more deformation of $2 \mathrm{~mm}$ can cause the role to change.

Whenever the $\mathrm{PH}$ values goes low, the coolant is unable to provide the required cooling and the temperature temporary increases up to $200-250{ }^{\circ} \mathrm{C}$

Thermal Strain $=\alpha . \Delta \mathrm{T}$

Here is our case, for D2 material value of $\alpha$ is $10.3 * 10^{-6} \mathrm{~mm} / \mathrm{mm}{ }^{\circ} \mathrm{C}$

So, the temperature deviation from room temperature is

$(250-25){ }^{\circ} \mathrm{C}=225^{\circ} \mathrm{C}$

So thermal strain is

$T_{s}=10.3 * 225 * 10^{-6} \mathrm{~mm} / \mathrm{mm}$

$=2340 * 10^{-6} \mathrm{~mm} / \mathrm{mm}$

Now,

Strain $=\Delta \mathrm{L} / \mathrm{L}$.

So,

$2340 * 10^{-6}=\Delta \mathrm{L} / \mathrm{L}$.

In our case the length is $400 \mathrm{~mm}$

$\Delta \mathrm{L}=0.936 \mathrm{~mm}$.

Similarly,

Whenever the Saponification values goes low, the coolant is unable to provide the required cooling and the temperature temporary increases up to $200-250{ }^{\circ} \mathrm{C}$

Thermal Strain $=\alpha . \Delta \mathrm{T}$

Here is our case, for D2 material value of $\alpha$ is $10.3 * 10^{-6} \mathrm{~mm} / \mathrm{mm}{ }^{\circ} \mathrm{C}$

So, the temperature deviation from room temperature is

$(250-25){ }^{\circ} \mathrm{C}=225^{\circ} \mathrm{C}$

So thermal strain is 
Comparison of Roll Deformation In 4hi Rolling Mill and 20 Hi Rolling Mill Due To Thermal Stresses, Overloading, Spalling and Design Parameters

$T_{s}=10.3 * 225 * 10^{-6} \mathrm{~mm} / \mathrm{mm}$

$=2340 * 10^{-6} \mathrm{~mm} / \mathrm{mm}$

Now,

Strain $=\Delta \mathrm{L} / \mathrm{L}$.

So,

$2340 * 10^{-6}=\Delta \mathrm{L} / \mathrm{L}$.

In our case the length is $400 \mathrm{~mm}$

$\Delta \mathrm{L}=0.936 \mathrm{~mm}$.

Similarly when the coolant status goes low, the temperature rises and a further deformation of $0.936 \mathrm{~mm}$ occurs as shown above by other factors.

So total deformation due to tension and temperature changes due to $\mathrm{PH}$ value, coolant and saponification value is $5.808 \mathrm{~mm}$ which will deform the role and make it unusable

Total number of times from 90 days when the temperature rises such high due to thermal stress in Jan - March $=45$ times.

Total number of times from 90 days when the temperature rises such high due to thermal stress in Apr - June $=35$ times.

Total number of times from 90 days when the temperature rises such high due to thermal stress in Jun - Aug $=37$ times.

Table 4 Research Parameters of Thermal Stresses in 20 Hi Mill

\begin{tabular}{|c|c|c|c|c|c|c|c|c|c|}
\hline $\mathbf{Q}$ & $\begin{array}{c}\mathbf{T} \\
(\mathbf{k N})\end{array}$ & $\begin{array}{c}\boldsymbol{L}_{\boldsymbol{p}} \\
(\mathbf{m m})\end{array}$ & $\boldsymbol{A}$ & $\begin{array}{c}\mathbf{R} \\
(\mathbf{m m})\end{array}$ & $\mathbf{S V}$ & $\boldsymbol{T}_{\boldsymbol{s}}\left(\mathbf{1 0}^{-\mathbf{6}}\right)$ & $\begin{array}{c}\boldsymbol{S}_{\boldsymbol{t}} \\
(\mathbf{M P a})\end{array}$ & $\mathbf{P H}$ & $\mathbf{N}$ \\
\hline Q1 & 50 & 2.44 & 2440 & 30 & 189 & 2340 & 20.75 & 7.14 & 45 \\
\hline Q2 & 50 & 2.44 & 2440 & 30 & 183.57 & 2340 & 20.75 & 6.78 & 35 \\
\hline Q3 & 50 & 2.44 & 2440 & 30 & 185.71 & 2340 & 20.75 & 6.93 & 37 \\
\hline
\end{tabular}

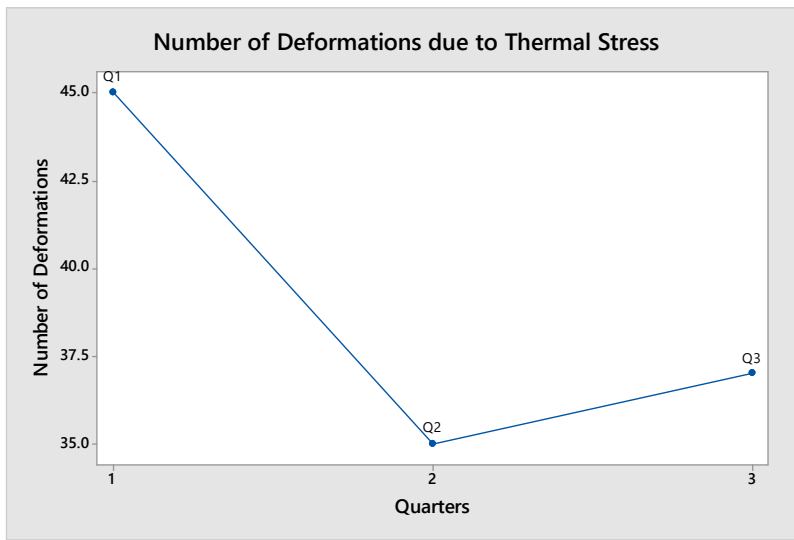

Figure 4 number of deformations vs three quarters of 20 hi mill (graph 5) 
Dr Ravi Kumar Goyal, Anurag Joshi and Umesh Gurnani

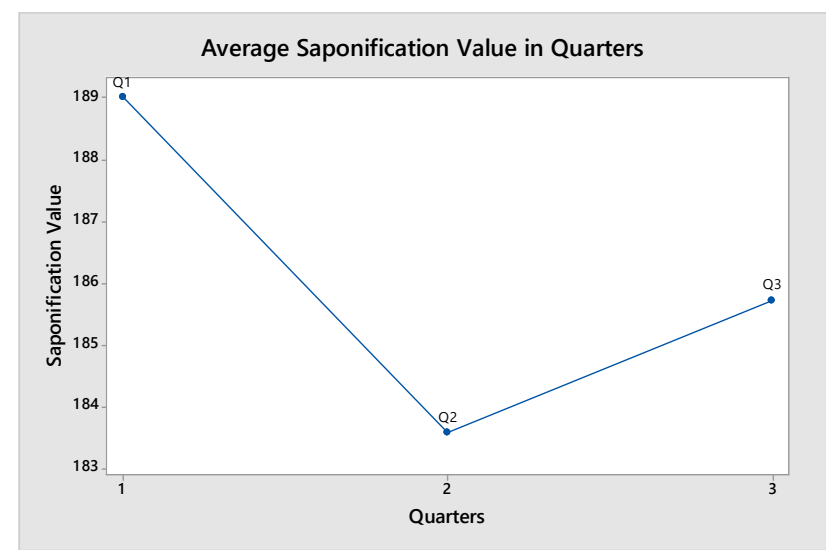

Figure 5 saponification value vs three quarters of 20 hi mill (graph 6)

\section{DEFORMATION DUE TO OVERLOADING}

Tension in the work roll according to provided data

$\mathrm{T}=41.5 \mathrm{kN}$

Area of tension, $\mathrm{A}=\mathrm{b} * L_{p}$

Where $\mathrm{b}$ is width of sheet and $L_{p}$ is projected length of arc of contact.

$\mathrm{A}=400 \mathrm{~mm} * L_{p}$

Now $L_{p}=\sqrt{R \Delta h}$ $[23][25]$

Where $\mathrm{R}$ is radius of work roll and $\Delta h$ is the difference of thickness of sheet.

Here $\Delta h$ is $0.2 \mathrm{~mm}$

And $\mathrm{R}$ is $125 \mathrm{~mm}$

So $L_{p}=\sqrt{25 m m * m m}$

$\mathrm{A}=400 * 5 \mathrm{~mm}^{2}$

So Stress due to tension is, $S_{t}=\mathrm{T} / \mathrm{A}$

$=41.5 \mathrm{kN} / 2000 \mathrm{~mm}^{2}=20.75 \mathrm{MPa}$

Strain $=$ Stress $/$ Young's Modulus

$=20.75 / 210$

$\Delta \mathrm{L} / \mathrm{L}=20.75 / 210$

$\Delta \mathrm{L} \sim \mathrm{L} / 10$

Now in our case the diameter is $250 \mathrm{~mm}$, so $\mathrm{L}=250 \mathrm{~mm}$

$\Delta \mathrm{L}=2.5 \mathrm{~mm}$.

A more deformation of $2.5 \mathrm{~mm}$ can cause the role to change.

The relationship between the $\Delta h$ and $\mathrm{M}$ (Mill Modulus) is expressed as

$h_{\text {out }}=S+F / M$ 
Comparison of Roll Deformation In 4hi Rolling Mill and 20 Hi Rolling Mill Due To Thermal Stresses, Overloading, Spalling and Design Parameters

Where $h_{\text {out }}$ is the exit strip thickness, $\mathrm{S}$ is work roll gap, and $\mathrm{F}$ is roll Force and $\mathrm{M}$ is Mill Modulus

Now, the mill modulus of Cold Rolling machine is nearly $1000 \mathrm{ton} / \mathrm{mm}$.... [21]

So, if we roll 22000 MT of sheets, the total deformations which occurs is

$(22000 * 1000) / 1000=22000 \mathrm{~mm}$

Now due to overloading only $10 \%$ to $20 \%$ roll changes occur

$10 \%$ of $22000 \mathrm{~mm}=2200 \mathrm{~mm}$.

If we consider that we changes the roll in every $100 \mathrm{~mm}$, total roll deformed will be equal to 22 in a quarter producing 22000MT.

Table 5 Research Parameters for Overloading

\begin{tabular}{|c|c|c|c|c|c|c|c|c|c|}
\hline $\mathbf{Q}$ & $\begin{array}{c}\mathbf{T} \\
(\mathbf{k N})\end{array}$ & $\begin{array}{c}\boldsymbol{L}_{\boldsymbol{p}} \\
(\mathbf{m m})\end{array}$ & $\boldsymbol{M M}$ & $\begin{array}{c}\mathbf{R} \\
(\mathbf{m m})\end{array}$ & $\mathbf{S V}$ & $\boldsymbol{T}_{\boldsymbol{s}}\left(\mathbf{1 0}^{-\mathbf{6}}\right)$ & $\begin{array}{c}\boldsymbol{S}_{\boldsymbol{t}} \\
(\mathbf{M P a})\end{array}$ & $\mathbf{P H}$ & $\mathbf{N}$ \\
\hline Q1 & 41.5 & 5 & 1000 & 125 & 188.35 & 566.5 & 20.75 & 8.64 & 22 \\
\hline Q2 & 41.5 & 5 & 1000 & 125 & 184.28 & 566.5 & 20.75 & 8.14 & 22 \\
\hline Q3 & 41.5 & 5 & 1000 & 125 & 183.28 & 566.5 & 20.75 & 7.46 & 22 \\
\hline
\end{tabular}

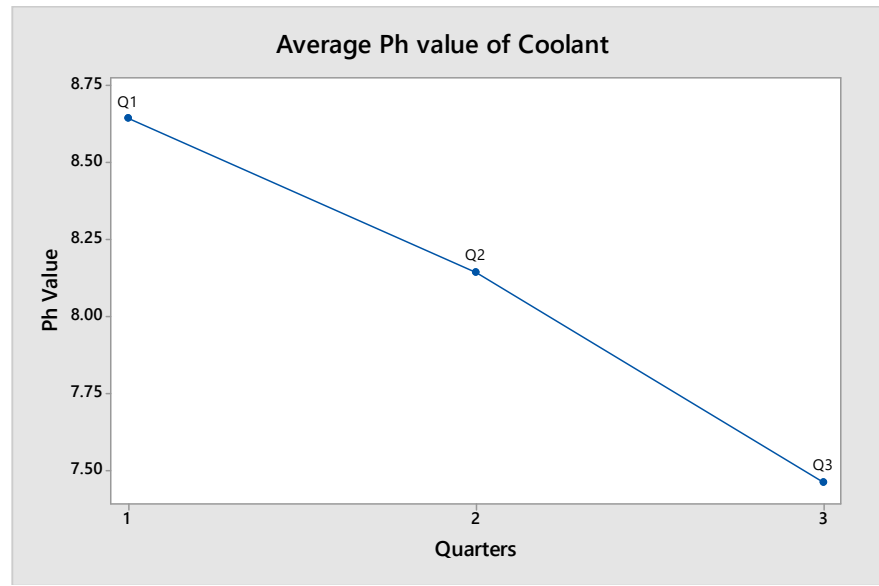

Figure 6 ph value of coolant vs three quarters (graph 3)

Similar calculations can be done for $20 \mathrm{Hi}$ Mill in case of deformation due to overloading as done for thermal stresses.

\section{DEFORMATION DUE TO SPALLING}

One of the major reasons of roll failure in cold rolling mill is Spalling. Many set of stress are subjected on work roll. The internal stresses resulting from the heat treatment is also a cause of spalling. Rolling operation mainly causes internal stress.

There are two types of Spalling

- Spalling which occurs due to fracture of which the origin starts from the surface of work roll or just beneath the work roll.

- Spalling due to fracture and the origin of the fracture starts inside the work roll. [24] 
Four major Reasons for Spalling are

1. When there is a huge difference between inlet tension and outlet tension causing a surface stress on the roll which than transform into a crack and then breakage.

2. Whenever due to low coolant, the saponification values goes down, which in turn lowers the coefficient of friction and many times the sheet to be rolled gets roll along with work roll causing the breakage of sheet as well as work roll .

3. Many times sheet breakage occurs due to various reasons and along with sheet breakage the work roll gets damage,

4. There is also a chance that the chemical composition of metal of work roll is not proper and there are casting and pouring effects.

Mathematically,

Thermal Strain $=\alpha . \Delta \mathrm{T}$

Here in our case, for D2 material value of $\alpha$ is $10.3 * 10^{-6} \mathrm{~mm} / \mathrm{mm}{ }^{\circ} \mathrm{C}$

The average temperature over month of Jan - March is $80{ }^{\circ} \mathrm{C}$.

So the temperature deviation from room temperature is

$(80-25){ }^{\circ} \mathrm{C}=55^{\circ} \mathrm{C}$

So thermal strain is

$T_{s}=10.3 * 55 \mathrm{~mm} / \mathrm{mm}$

$=566.5 * 10^{-6} \mathrm{~mm} / \mathrm{mm}$

Stress due to thermal Strain

$T_{s t}=\mathrm{E} * T_{s}$

Where E is Young's Modulus

E for D2 material is $210 \mathrm{GPa}$

$T_{\text {st }}=210 \mathrm{GPa} * 566.5 * 10^{-6}$

$=118 \mathrm{MPa}$

Tension in the work roll according to provided data

$\mathrm{T}=41.5 \mathrm{kN}$

Area of tension, $\mathrm{A}=\mathrm{b} * L_{p}$

Where $\mathrm{b}$ is width of sheet and $L_{p}$ is projected length of arc of contact.

$\mathrm{A}=400 \mathrm{~mm} * L_{p}$

Now $L_{p}=\sqrt{R \Delta h}$ 
Comparison of Roll Deformation In 4hi Rolling Mill and 20 Hi Rolling Mill Due To Thermal Stresses, Overloading, Spalling and Design Parameters

Where $\mathrm{R}$ is radius of work roll and $\Delta h$ is the difference of thickness of sheet.

Here $\Delta h$ is $0.2 \mathrm{~mm}$

And $\mathrm{R}$ is $125 \mathrm{~mm}$

So $L_{p}=\sqrt{25 m m * m m}$

$\mathrm{A}=400 * 5 \mathrm{~mm}^{2}$

So Stress due to tension is, $S_{t}=\mathrm{T} / \mathrm{A}$

$=41.5 \mathrm{kN} / 2000 \mathrm{~mm}^{2}$

$=20.75 \mathrm{MPa}$

Total Stress $=(118+20.75) \mathrm{MPa}$

$=138.75 \mathrm{MPa}$

Now, For D2 material the tensile strength is $1916 \mathrm{Mpa}$.

Due to low $\mathrm{PH}$ and low saponification value, temp may rise up to $200{ }^{\circ} \mathrm{C}$ and may increase the stress further. When the stress reaches $1916 \mathrm{MPa}$, the work roll gets a fracture.

Also the friction coefficient,

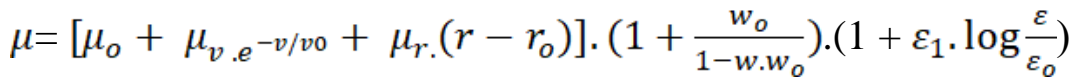

Variables in friction coefficient depends on lubricants, saponification value, bearing,PH , nozzle spray etc.

When the friction drops down the sheet rolls along with work roll and fracture occurs.

From data,

Total number of times from 90 days when the friction coefficient drops such low due to Spalling in Jan - March $=10$ times.

Total number of times from 90 days when the friction coefficient drops such low due to Spalling in Apr - June $=8$ times.

Total number of times from 90 days when the friction coefficient drops such low due to Spalling in Jun - Aug = 13 times.

Table 6 Research Parameters of Spalling

\begin{tabular}{|c|c|c|c|c|c|c|c|c|c|}
\hline $\mathbf{Q}$ & $\begin{array}{c}\mathbf{T} \\
(\mathbf{k N})\end{array}$ & $\begin{array}{c}\boldsymbol{L}_{\boldsymbol{p}} \\
(\mathbf{m m})\end{array}$ & $\begin{array}{c}\Delta \boldsymbol{h} \\
(\mathbf{m m})\end{array}$ & $\mathbf{S V}$ & $\begin{array}{c}\mathbf{T S} \\
(\mathbf{M p})\end{array}$ & $\boldsymbol{T}_{\boldsymbol{s}}\left(\mathbf{1 0}^{-\mathbf{6}}\right)$ & $\begin{array}{c}\boldsymbol{S}_{\boldsymbol{t}} \\
(\mathbf{M P a})\end{array}$ & $\mathbf{P H}$ & $\mathbf{N}$ \\
\hline Q1 & 41.5 & 5 & 0.2 & 188.35 & 1916 & 566.5 & 25 & 8.64 & 10 \\
\hline Q2 & 41.5 & 5 & 0.2 & 184.28 & 1916 & 566.5 & 25 & 8.14 & 8 \\
\hline Q3 & 41.5 & 5 & 0.2 & 183.28 & 1916 & 566.5 & 25 & 7.46 & 13 \\
\hline
\end{tabular}




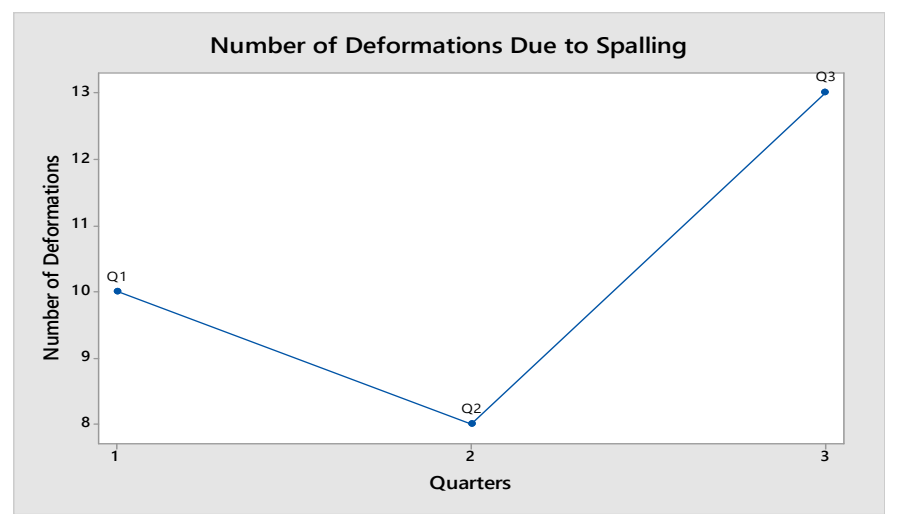

Figure 7 number of deformed rolls vs quarters (graph 4)

Similar calculations can be done for $20 \mathrm{Hi}$ Roll as done in case of deformation due to thermal stresses and overloading

\section{DEFORMATION DUE TO DESIGN}

There are mostly no failure of Roll due to design parameters.

\section{CONCLUSION}

The reasons which are responsible for the breakage were highlighted. The reasons for roll deformation in cold rolling mill were studied. The work is determined by detailing the roll manufacturing at Supreme Rolls and Shears Pvt Ltd Indore and Dee Tee Industries Indore which are producing Rolls for various rolls for Indigenous and other export suppliers. The working of the rolls in rolling mill is studied at Ruchi Strips and Alloys Ltd, Indore and ASIL Industries at Jaipur which are having 20Hi and 4Hi rolling mills and are the customers of above mentioned Roll Manufacturing Companies. Several suggestions have also been made for smooth operation of the mill and consequently for the extension of life of a work roll. The following conclusions made after analysis:

1. The deformations in $20 \mathrm{Hi}$ rolling mill are high than $4 \mathrm{Hi}$ rolling mill.

2. Major factors responsible for roll deformations are thermal stress, overloading and spalling.

3. The selection of material, the production sequence, heat treatment and machining are having vital importance on the life of a roll.

4. In small diameter roll a thin sheet can be produced whereas large diameter rolls can produce medium thickness of the sheet.

5. The mechanical properties are greatly affected if the process parameters are changes. 


\section{REFERENCES}

[1] K.K. Singh et. al., (2011) Detection of defects on Cold Rolling Mill (CRM) rolls with Ultrasonic \& Eddy current law detectors, , NDESAI Jamshedpur, India

[2] Soszyński, A. Studnicka, BIPROMET S.A. ul. Graniczna (2012) A review of contemporary solutions for cold rolling that allow quality improvement, W. 29, 40-956 Katowice, Poland, International OCSCO world press

[3] Shiang-Cheng Jeng and Horng-ShingChiou (2011) Analysis of surface spalling on a First Intermediate Roll in Sendzimir Mills, , World Academy of Science, Engineering and Technology 57

[4] Shen et. al.,(2008), Influence of Rolling Chemicals on temper rolling process and anti rust performance of cold rolled steels, China Technical Report, No. 21, pp. 45-51

[5] Mackel (2000) Maintenance and quality related condition monitoring in rolling mill, AISE, Chicago, Illinois/USA

[6] Seeligeret. al. (2002), Measurement and diagnosis of process - disturbing oscillations in High speed rolling plant, IMEKO, Tampere, Finland.

[7] Ahmad Saboonchi , Sayyed Majid Aghili (2006), The effect of Header Geometry on Temperature Distribution in Cold Rolling, International Journal of ISSI, Vol 2, No.2, pp. 24-29

[8] Anand S. Nilewar, SharadChaudhari and PrafullaChaudhari (2013) A Study Of Lubrication And Its Effect On Steel In Cold Rolling Mill : A Review VSRD International Journal of Mechanical, Civil, Automobile and Production Engineering, Vol. 3 No.3 e-ISSN : 2249-8303, p-ISSN : 23192208, pp.87-92

[9] CAO Jian-guo ,XU Xiao-zhao, SONG Mu-qing, ZHANG Jie, GONG Gui-liang, ZENG Wei (2011) Preset Model of bending force on 6-high reversing cold rolling mill based on genetic algorithm J. Cent. South Univ. Technol. 18: 1487- 1492 DOI:10.1007/s11771-011-0864-6

[10] Nakayama Katsumi Kuchi Masahiro Ogawa Shu Matsuzawa Tsukasa SATO Kazuyuki Characteristics and Line-up of IHI's Non-Ferrous Metal Rolling Mills pp 28-34

[11] A G Atkins Hydrodynamic Lubrication in Cold Rolling Int..J.mech.Sci.Fergamon Press. 1974, Vol- 16, pp 1-19

[12] I. Schindler, M. Janošec, E. Místecký, M. Rù.ièka, L. Ėí.ekL.A. Dobrzañski , S. Rusz , P. Suchánek (2009) Effect of cold rollingand annealing on mechanical properties of HSLA steel Archives of Material Science and Engineering, Vol-3 Issue-1, pp 41-47

[13] Limei Jing (2003), Rolling Mill Roll Design, Durham E Theses, School of Engineering, University of Durham

[14] Z. Y. Jiang,Mechanics of Cold Rolling of Thin Strip, School of Mechanical, Materials and Mechatronic Engineering, University of Wollongong, Wollongong, Australia 
[15] UmutHanoglu, Supervised by Prof. BožidarŠarler, Mathematical and physical modeling of flat rolling process

[16] M.Malvezzi, M.C. Valigiinfluence Of Plastic Deformation Models In Fullfilm Lubrication Ofstrip Rolling, AITC-AIT 2006, International Conference on Tribology , 20-22 September 2006, Parma, Italy.

[17] Frantisek Durovsky (2008), Computation of Rolling Stand Parameters by genetic Algorithm, ActaPolytechnicaHungarics, Vol 5, No2.

[18] Jian et al [2008], Finite element analysis of strip and rolling mills, University of Science and Technology, Beijing, China, Vol 2, No 5.

[19] Wendt, Winfried and Leifgen (2007), Cold Rolling defects, "Stickers" and countermeasures, Heat Processing - International magazine for industrial furnaces, Heat treatment plant and equipments, ISSN 1611-616X, Vol 2.

[20] John M. Sech, David I. Weinstein, E. Michael Kerr (1989), The Evaluation of Rolling Oil used in the cold Rolling Process for Sheet steel by Thermogravity, Journal of the Society of Tribologists and Lubrication Engineers, Vol 46.5, pp 297-300.

[21] Chapter 3, Working, Heat Treatment and Surface Treatment ,Kawasaki JFE $21^{\text {st }}$ Century Foundation

[22] Waleed I. Hameed, Khearia A. Mohamad Department of Electrical Engineering, University of Basrah, Basrah, Iraq ,Engineering, 2014, 6, 27 33 Published Online January 2014

[23] Z. Y. Jiang, School of Mechanical, Materials and Mechatronic Engineering,University of Wollongong, Wollongong, Australia.

[24] A. K. Ray, K. K. Mishra \& P. N. Chaudhary , Proceedings: Cofa1997,Nml Jamshedpur; pp. 37-46

[25] J.Yang. Mathematical model of rolling process. Beijing: Press of Metallurgical Industry, 1983 (in Chinese)

[26] Chen Shu-zong, Zhang Dian-hua, Sun Jie, Wang Jun-sheng, Song Jun , Online Calculation Model of Rolling Force for Cold Rolling Mill Based on Numerical Integration, The State Key Laboratory of Rolling and Automation, Northeastern University, Shenyang, Liaoning, 110819, China

[27] TapanyUdomphol, Suranaree University of Technology, Rolling of metals, Chapter 3 